\title{
Comparison of nitrogen contents in Survenola grass, Pangola grass and Alfalfa
}

\author{
Jia-Twu Lee*, Wu-Chou Yu \\ Department of Environmental Science and Engineering, \\ National Pingtung University of Science and Technology Pingtung 91201, Taiwan.
}

\begin{abstract}
Biofertilizers depend on special bacteria to enhance the uptake by plants of water; to accelerate growth; to increase the absorption of minerals by plants; to reduce the long production times that are required to use organic fertilizer, and to improve the volume and quality of crop production. This study examines the application of organic fertilizer under grass and the relationship between the soil and the nutrients in the body of plants.
\end{abstract}

Field tests were performed in 24 small test areas within a larger area of grass. The small test area were planted with Pangola grass, Survenola grass and Alfalfa. A comparison of nitrogen contents in the plant bodies in the areas that were planted with Survenola, Pangola grass, and Alfalfa, revealed that the nitrogen content of Alfafa greatly exceeded that of Pangola grass. A comparison of phosphorus contents in the plant bodies of Survenola, Pangola grass and Alfalfa reveals that the phosphorus content of the Survenola grass considerably exceeds that of the Pangola grass. The potassium contents in Survenola grass, Pangola grass, and Alfalfa are also compared. That of Survenola grass significantly exceeds that of Pangola grass.

Grass production analysis demonstrates that the application of organic fertilizer or the planting of a single plant rather than mixed plants does not significantly affect production weight.

key words - Organic fertilizers, Survenola grass, Pangola grass, Alfalfa

\section{INTRODUCTION}

Taiwan's total area of 360 million hectares consists of 950,000 hectares of planes, around 970,000 hectares of hillside and around1.68 million hectares of high mountains. About 865,723 hectares (Ministry of Economic Affairs Water Resources Agency, 2010) is agricultural land, covering a large fraction of Taiwan's total area. Taiwan generates large volumes of agricultural waste, the use of which is attracting increasing attention in Taiwan, with a view to using resources more efficiently. As environmental awareness increases, more attention is being paid to environmentally friendly organic agriculture, but much is being paid to agriculture that uses chemical fertilizers , which have an impact on affect the environment. During the industrial revolution, chemical fertilizers began to be used in large quantities of chemical fertilized began to be used. Since the use of such chemical fertilizers rapidly affects crop production volumes, they have greatly replaced traditional organic fertilizers, and are used widely today.
The extended heavy use of chemical fertilizers with little use of organic fertilizers has reduced soil activity, detrimentally affecting he balance of existing eco-systems. Lockeretz [1] observed that the heavy use of nitrogen fertilizer accelerates the soil acidification. Boone [2] also noted that the excessive use of nitrogen fertilizer causes the pollution of groundwater by nitrogen. Humans also ingest excessive amounts of nitrogen in the form of nitrates that accumulate in crops, detrimentally affecting their health [3]. Additionally, the flow of excess phosphorus into rivers and lakes causes eutrophication. Therefore, the global agricultural community has begun to advocate sustainable agricultural business practices, including the use of organic fertilizer to maintain soil activity. Traditional organic agriculture has therefore thus once again become important and substantial research is being performed in this area in several countries in 1998, Taiwan began to study and promote organic farming [4]. Its study and promotion program focused on reducing or limiting the use of chemical fertilizers, and ensuring the sustainability of Taiwan's agricultural businesses. The organic agricultural model will be standardized, and prohibitions or limitations of the use of chemical fertilizers are inevitable. Hubbell [5] pointed out that several scholars recommend the use of microbial fertilizers or fertilizer materials, including biofertilizer, to promote biological nitrogen fixation to support agricultural production in developing countries. The use of biofertilizers is profitable Some of them rely on special bacteria to enhance the uptake of water by plants, their growth [6,7] and their mineral absorption, as well as to help reduce the long production times of other organic fertilizer, with the ultimate purpose of improving crop production volume and quality [8-12]. This study investigates the application of organic fertilizer under grass, and the relationship between the of the soil and the nutrients in the bodies of the plants. This ultimate goal of this study is to help maintain the ecological environment, and to make it environment sustainable by reducing the need for excessive soil cultivation [13].

\section{EXPERIMENTAL METHOD}

\section{A. Selecting grass for use in experiment}

Pangola grass 
Pangola grass is a species of hay forage that grows in Taiwan and is native to Africa. Pangola grass (Digitaria eriantha) is a low-growing creeping perennial that produces stolons runners. These stolons can grow 2-3 m during the wet season and form dense tufts. Pangola grass can adapt to a wide range of $\mathrm{pH}$ values, from 4.5 to 8.5 , and is moderately tolerant of aluminum, tolerating up to $34 \%$ saturation in the soil. Pangola grass is also moderately tolerant of soil salinity

\section{Survenola grass}

Survenola grass are closely related strains, which were introduced from Florida, USA

\section{Alfalfa}

Alfalfa is a perennial leguminous herb, which can adapt to various climatic and soil conditions. It can survive in the dry season; can be used as forage, a green manure crop or an ornamental plant. It is distributed throughout temperate regions of the world.

\section{B. Field experiment}

Field trials were performed using organic fertilizer with mixed grass and legume plants. The experiment involved Pangola grass, Pangola grass with Alfalfa, Survenola grass, Pangola grass with Alfalfa, and Alfalfa.

Each block contained either mixed plants or a single plant. The tested blocks were treated with agricultural livestock waste as an organic fertilizer and also with a chemical fertilizer.

Figure 1 presents blocks numbers 1, 2, and 3, and shows the species and numbers of plants in each block. The middle block and lane is separated into upper and lower regions. The Pangola grass upper block region comprises single planted Pangola grass and Pangola grass planted with Alfalfa. The lower block and region comprises single planted Survenola grass and Survenola grass planted with Alfalfa. In the gray blocks in the test site, agricultural animal waste was added as an organic fertilizer. The soil $\mathrm{pH}$ was measured using the glass electrode method. The nitrogen content of the soil was determined using EPA method 3010. Its phosphorus content was determined using Olsen's sodium bicarbonate method. Its potassium content was determined using a spectrophotometer. The quantity of organic matter in the soil was determined using EPA method 3310. The implant of the grass plant was analyzed using same as soil analysis procedure.

\section{RESULTS AND DISCUSSION}

Field tests and sampling were performed from February 2008 to September 2009. The optimal time for sampling the grass was during the harvest period. Six quarterly harvestings were carried out during the study period. When the grass was harvested, both it and the soil were immediately sampled. The harvested grass was dried and crushed, and test samples were collected from this material. The grass sample and soil were analyzed to determine the organic matter content, nitrogen content in the form of nitrate, effective nitrogen content, phosphorus content and potassium content and $\mathrm{pH}$ of the soil.

\section{A. Planted growth}

Figure 2 shows the recorded grass growth following harvesting. Figure 2 -a presents results for a single plant, while Figs. 2-b and c present results for mixed plants and the purple Alfalfa flower.

\section{B. Site of soil analysis}

The experimental field test was performed in Kenting Ranch . Soil was collected from the field. The test area was divided into 24 small blocks. In regions 1-6, a single grass plant was planted. Regions 1-3 were planted with Pangola grass, while regions 4-6 were planted with Survenola grass. Regions 7-12 were planted with Alfalfa . Regions 7-9 were planted with Pangola grass and Alfalfa; Regions 10- 12 were planted with Survenola grass mixed Alfalfa. Regions 13 - 18 were planted with a single grass. In regions 13-15, Pangola grass was cultivated, while in regions 16-18, Survenola grass was cultivated. Regions 19-24 were planted with mixed plants. In regions 19-21, Pangola grass was mixed with Alfalfa plant. In regions 22-24, Survenola grass was mixed with Alfalfa plants. Organic fertilizer was used in regions $3,4,5,9,10,11,15$ and 21 .

\section{Organic matter}

Figure 3 reveals that the amount of organic matter in the soil varied only slightly among the three batches of experiments.

\section{Ammonia nitrogen}

The ammonia content of the soil varied significantly in)the three batches of samples. The decrease in ammonia content in the time series of values may be related to the transformation of ammonia into nitrate, as displayed in Fig. 4

Nitrogen as nitrate

Figure 5 demonstrates that the nitrogen content of the form of nitrate in the three batches of samples increased with time.

\section{Effective nitrogen}

Figure 6 reveals that the effective nitrogen content gradually increased with time. Effective nitrogen refers to both ammonia and nitrate. Plants require effective nitrogen to grow.

\section{Phosphorus}

The analysis of phosphorus content indicates that the phosphorus content of the soil gradually decreased with time, perhaps because phosphorus is transformed into the grass body, as presented in Fig. 7. 
Potassium

The potassium content of the soil gradually declined with time, perhaps because the potassium was transferred into the bodies of the plants. The potassium content in soil as displayed in Fig. 8.

$\mathrm{pH}$

Soil $\mathrm{pH}$ does not significantly change overtime, as plotted in Fig. 9.

\section{Analysis of content of plant body}

Thirty-six samples of the plant bodies were collected for testing. Plant bodies 1-3, 7, 9, 11, 19-21, 25, 27 and 29 are Pangola grass. Plant bodies 4-6, 13, 15, 11, 17, 22-24, 31, 33 and 35 are Survenola grass. Plant bodies 1-3, 7, 9, 11, 19-21, 25, 27 and 29 are Pangola grass. Plant bodies 8, 10, 12, 14, 16, 18, 26, 28, 30, 32, 34 and 36 are Alfalfa. Plant bodies 3, 4, 5, $14,11-16,21,26,29,30$ and 32 were organically fertilized.

Nitrogen concentration in plant body

The nitrogen contents of plant bodies in the areas that were planted with Survenola, Pangola grass and Alfalfa were compared. The nitrogen content of Alfafa greatly exceeded that of Pangola grass, as presented in Fig. 10. Alfafa can directly absorb effective nitrogen which was converted from nitrogen in the air by bacteria. The alfafa plant body had a higher nitrogen content than Pangola grass.

Phosphorus concentration in plant body

A comparison of the phosphorus contents in the bodies of the Survenola, Pangola grass, and Alfalfa plants, indicates that the phosphorus content of the Survenola grass exceeded that of the Pangola grass, as presented in Fig. 11. Survenola grass can easily absorb phosphorus.

\section{Potassium concentration in plant body}

The potassium contents in Survenola grass, Pangola grass, and Alfalfa are compared. That in Survenola significantly exceeded that in Pangola grass, as displayed in Fig. 12. Survenola grass can easily absorb potassium.

\section{Statistical analyses of soil and plant body contents}

Comparison of nitrogen contents in soil in which are grown Pangola grass and Survenola grass with and without fertilization

The standard deviation of nitrogen content was significantly lower in the organically fertilized region. Since organic fertilization causes bacteria to release nitrogen slowly, the standard deviation of the nitrogen content in the organically fertilized soil was small.

Comparison of compositions of soil planted with Pangola grass alone and Pangola grass mixed with Alfafa.
Soil composition does not differ significantly between the areas of single-planted Pangola grass and Pangola grass planted with Alfalfa.

Comparison of compositions of soil in which Survenola grass alone and Survenola grass with Alfalfa are planted

The soil in which Survenola grass is planted differs considerably in potassium content from the soil in which it is planted with other plants. The mean organic matter and phosphorus contents are higher the soil in which the Survenola grass is mixed with Alfalfa. The standard deviations of these contents are lower than those in the soil in which Survenola grass alone was planted.

Comparison of nitrogen contents in soils in which are grown Pangola grass and Survenola grass with organic and nonorganic-fertilization

The data on nitrogen reveal that organic fertilization and non-organic fertilization do not significantly change nitrogen content, indicating no significant changes in the levels of the nutrients phosphorus and potassium. The standard deviation of the phosphorus and potassium nutrient contents in Pangola grass with organic fertilization is smaller than that with nonorganic fertilization..

Comparison of nutrient contents in plant bodies of Pangola grass mixed with Alfalfa and Survenola grass mixed with Alfalfa

The nutrient contents of the plant bodies of single-planted Pangola grass were compared with those of Pangola grass that was mixed with Alfalfa. The statistical results reveal that the nitrogen and potassium contents in Pangola grass plant are significantly differ significantly from Survenola. The nitrogen and potassium contents of the plant bodies of Pangola grass that was mixed with Alfalfa were higher than those of Pangola grass alone . A statistical comparison of the nutrient contents of the plant bodies of single-planted Survenola grass and Pangola grass mixed with Alfalfa. The statistical results indicate that the nitrogen and phosphorus contents in Survenola grass plant are significantly Pangola grass. The nitrogen and phosphorus contents of the plant bodies of Survenola grass that is mixed with Alfalfa are higher than those of Survenola grass planted alone.

\section{E. Production analysis}

Pangola grass and Taiwanese Survenola grass are the same species, and can be harvested six times per year. The relationship between the production of grass achieved using organic fertilizer and the standard deviation of the production weight The standard deviation of the weight of Pangola grass grown in certain area using organic fertilizer is 2.83 tons. Under the same conditions but without organic fertilizer, the production weight has a standard deviation of 3.8 tons. Comparing the production data for the two grasses reveals no statistically significant difference in mean production weight. 


\section{CONCLUSIONS}

This study tested soil nutrients for organic matter, nitrate nitrogen content, ammonia nitrogen content, effective nitrogen content, phosphorus content, potassium content, and $\mathrm{pH}$. The objective was to understand the application of organic fertilizers and the mixed planting of crops with leguminous plants. Organic fertilizers affect the soil and the nutrient contents of plants. Soil nutrients directly and indirectly influence affect crop production volumes. This study draws the following conclusions

The application of organic fertilizers to grassland increases organic matter content, nitrogen content, phosphorus content and potassium content. Such fertilizers reduce change soil $\mathrm{pH}$, improving soil quality, because they release nutrient slowly. The organic fertilizer releases nutrient more slowly than chemical fertilizer in the body of the grass. The organic matter maintains and even improves plant nutrient content, although the effect is not significant even over the long-term.

\section{REFERENCES}

[1] Lockeretz, W., Energy input for nitrogen,phosphorus, and potash fertilizers, Handbook of Energy Utilization in Agriculture, 1980,pp.23-241.

[2] Liu ,Yitai , David R. Boone and Choy , Chee. , Methanohalophilus oregonense sp. nov., a methylotrophic methanogen from an alkaline, saline aquifer , IJSEM ,April $1990,40(2), 111-116$.

[3 ]Wolff , I. A. and Wasserman ,A. E.,Nitrates,nitrites and nitrosamines, Science, 1972, pp.3701

[4]Chen , Zueng-Sang ,Sustainable agriculture soil quality assessment and land management strategies, Workshop on Advances Album Sustainable Agricultural Research and Extension,1995,pp.16-33 ,83 years in November 23-25, Taichung, Taiwan[in chinese]

[5] Hubbell , Jeffrey A. ,Biomaterials in tissue engineering, Nature Biotechnology, 1995,vol.13, pp.565 - 576.

[6] Buwalda ,J.G ., Stribley , D.P. and Tinker , P.B., Increased uptake of anions by plants with vesicular-arbuscular mycorrhizas, Plant and Soil ,1983,vol.71( 1-3),pp.463-467.

[7] Buwalda , J.G., Stribley D.P. , and Tinker, P.B., The development of endomycorrhizal root systems V. The detailed pattern of development of infection and the control of infection level by host in young leek plants, New Phytologist, 1984,96(3) , pp.411427, March

[8] Barea ,J.M. , Azcon-Aguilar C., Azcon R. ,Vesicular-arbuscular mycorrhiza improve both symbiotic N2 fixation and N uptake from soil as assessed with A15 $\mathrm{N}$ technique under field conditions, New Phytologist, 1987,106(4), pp.717-725, August .

[9] Bitzer, C. C., and Sims, J. T. ,Estimating the availability of nitrogen in poultry manure through laboratory and field studies, $\mathrm{J}$. Environ. Qual. 1988,vo.17, pp.47-54.

[10] Chang, C., Sommerfeldt , T. G., and Entz, T.,Soil chemistry after eleven annual applications of cattle feedlot manure, J. Environ. Qual. 1991,vol.20, pp.475-480

[11] Chen, J. H., Wu , J. T. and Huang, W. T. ,Effects of compost on the availability of nitrogen and phosphorus in strongly acidic soils, Technical Bulletin, Food \& Fertilizer Technology Center ,2001.vol.1, pp.1-10. [in Chinese]

[12] Choudhary, M., Bailey , L. D., and Grant , C. A., Review of the use of swine manure in crop production: effects on yield and composition and on soil an water quality, Waste Management \& Research, 1996,vol.14, pp.581-595.

[13] Eghball, B., Binford , G. D., and Baltensperger, D. D., Phosphorus movement and adsorption in a soil receiving longterm manure and fertilizer application, J. Environ. Qual., 1996,vol. 25, pp.1339-1343.

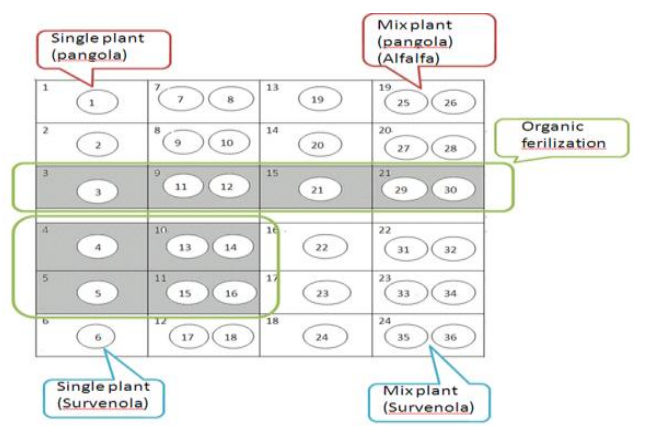

Figure 1. Experimental configuration.

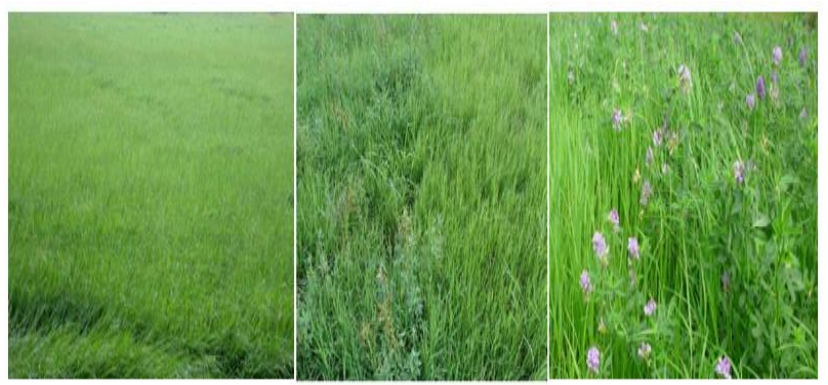

(a)

(c)

(b)

Figure 2. Growth of plants in field experiment

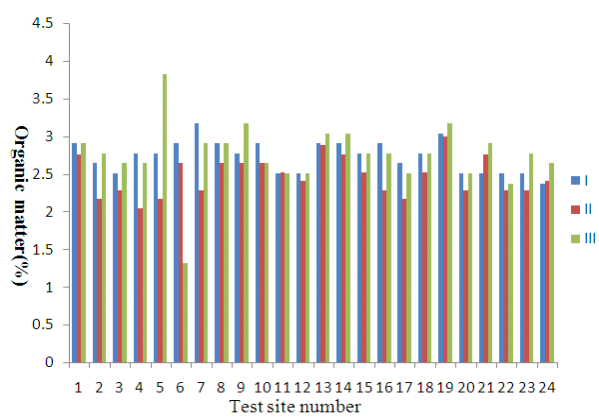

Figure 3. Organic matter in soil in which are grown three batches of samples.

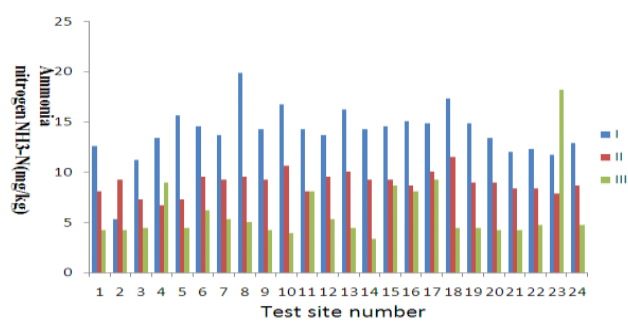

Figure 4. Ammonia-nitrogen contents in soils in which are grown three batches of samples. 


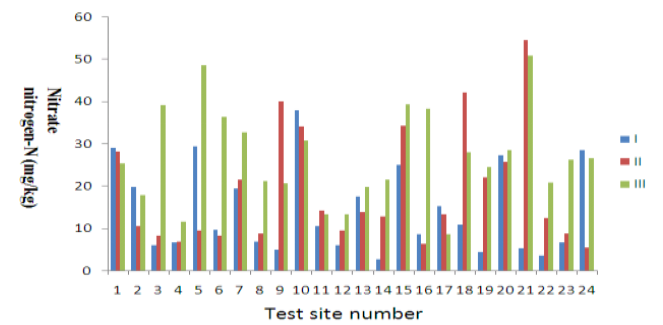

Figure5.Nitrate-nitrogen concentration in soils in which are grown three batches of samples.

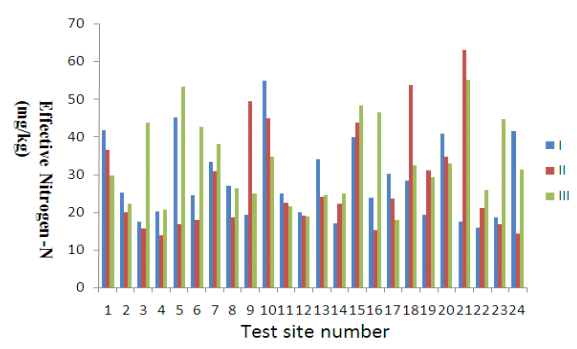

Figure 6. Effective nitrogen concentration in soils in whichare grown three batches of samples.

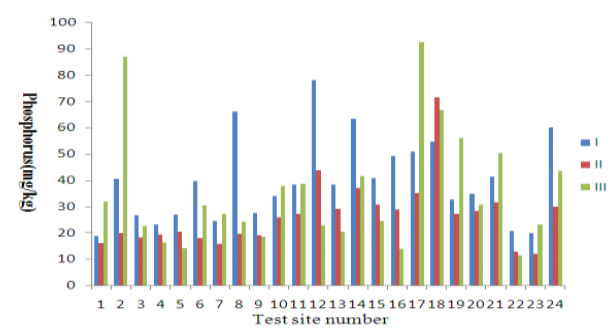

Figure 7. Phosphorus concentration in soils in which are grown three batches of samples.

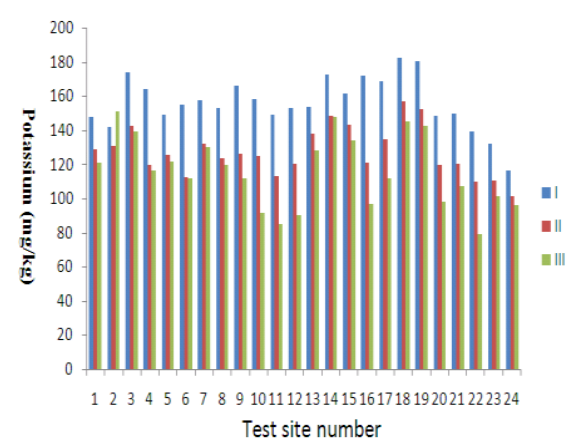

Figure 8. Potassium concentration in soils in which are grown three batches of samples.

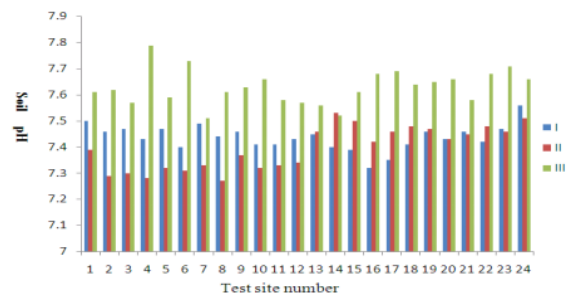

Figure 9. $\mathrm{pH}$ value of soils in which are grown three batches of samples.

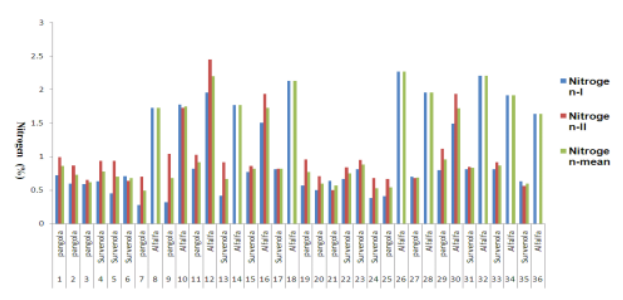

Plant body

Figure 10. Nitrogen concentration in plant body.

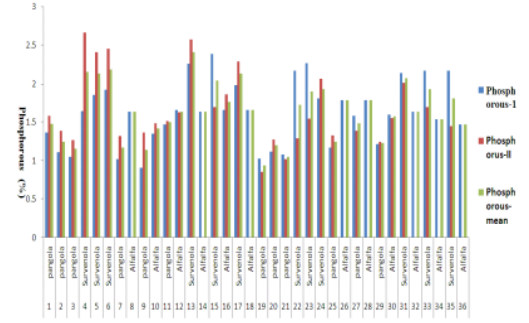

Plant body

Figure 11. Phosphorous concentration in the plant body .

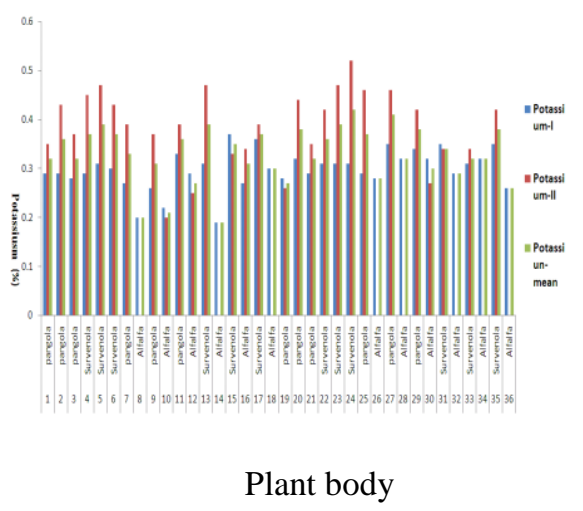

Figure 12. Potassium concentration in plant body. 